\title{
Research on the Applicability of Low-tech Bamboo Architecture in New Rural Construction
}

\author{
Yuan Xinping ${ }^{1}$, Ji Chenhao ${ }^{1,2, a}$, Wang Xueying ${ }^{1}$, Luo Zilong ${ }^{1}$ and Jin Yucheng ${ }^{1}$ \\ ${ }^{1}$ Academy of Art and Design, Wuhan University of Science and Technology, Hongshan District, Wuhan City, Hubei Province, China \\ ${ }^{2}$ New Rural Construction Research Center, Wuhan University of Science and Technology, Hongshan District, Wuhan City, Hubei \\ Province, China
}

\begin{abstract}
Bamboo resources are abundant in China, and low-tech bamboo structures are used to maximize the sustainable development of new rural construction. This paper will deeply explore, study and analyze the issue of low-tech bamboo construction, then further analyze its applicability in new rural construction, and ultimately find a feasible plan about bamboo construction, so as to take effective measures to combine new rural construction and green science and technology.
\end{abstract}

\section{Analysis of existing bamboo processing technique}

\section{1 Existing techniques at home and abroad}

\subsubsection{Development and application status of foreign bamboo processing technique}

Compared with the current status of the domestic use of bamboo materials, some foreign architects' design works appear to be more in-depth and innovative. They have designed high-quality works by continuously exploring the material properties and construction logic of bamboo materials so that people have an avant-garde awareness of bamboo construction, which plays a more important role in the promotion of the use of bamboo materials ${ }^{[1]}$. Scholars from the United States, Germany, Japan, and other countries have worked on various innovative and forward-looking research practices for the promotion of bamboo materials, and their designs of bamboo architecture and art installations have brought different sensory experiences to the world. Meanwhile, it demonstrates the rich and colorful possibilities of bamboo structures.

Famous designers from different countries of the world are invited to the International Bamboo Architecture Biennial Exhibition to participate in the construction of the architecture in the way of writing propositions. The biennale fully respects the aboriginal customs, history, and ecology, and carefully sorts out the collective memory of the rural areas through an international perspective, and uses the "bamboo" as a carrier to integrate culture into architectural design.

"The stones of other hills can be used to attack jade." Studying outstanding foreign architects and artists and summarizing their works will become an important part of

\footnotetext{
*Corresponding author: ${ }^{a}$ jichenhao3211@foxmail.com
}

the development of the fundamental domestic bamboo structures, as well as one of the effective means of changing the lagged development of domestic bamboo materials and adopting bamboo construction techniques widely.

\subsubsection{Development and application status of foreign bamboo processing technique}

Currently, the application of domestic bamboo construction technique is relatively narrow and the development of bamboo construction is slow. Few excellent bamboo architectural works are designed by Chinese architects. Such excellent works as Mr. Feng Jizhong's design of the "Helou Pavilion" in the Shanghai Square Pagoda Garden are extremely rare in China ${ }^{[2]}$. Bamboo materials begin to be widely used in temporary or low-quality buildings such as theme hotels, holiday resorts, and park figurines with a relatively simple method. Most of buildings are made by simply replacing wood with bamboo. Many extraordinary characteristics of bamboo have not been well represented in such a treatment. From a macro perspective, there are few outstanding bamboo buildings in China.

In the overall situation where the use of bamboo is relatively lag-behind, some scholars in China still have conducted some in-depth research in this field. Professor Xiao Yan from Hunan University has conducted an in-depth study of the material characteristics and mechanical properties of bamboo from the perspective of structural engineers. In December 2007, the world's first fully bamboo-structured bridge with access to vehicles was completed and opened to traffic in Leiyang, Hunan Province. This fully bamboo-structured bridge bears an actual carrying capacity of approximately 90 tons and a span of 10 meters ${ }^{[3]}$ The team led by Professor Xiao Yan, has also designed and made a number of bamboo-structured residential buildings with earthquake-resistance capacity up to level 8 , which has also set a precedent for the Chinese architectural field. 
Professor Xiao Yan's research center mainly works on fields of materials, mechanics, and engineering technology. There are relatively few studies on the issues of form, space, and construction of architectural design. Professor Xiao Yan's pioneering work can only be regarded as the top level work in China. Although the theories and practices of bamboo construction have been increasingly valued in the field of architecture in China, the overall level of development is still relatively backward.

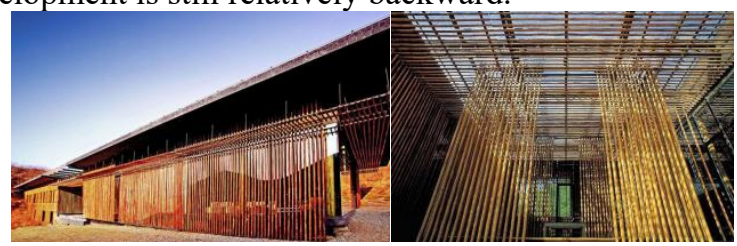

Figure 1.

Figure 2.

The bamboo house of the commune at the foot of the Great Wall, Kengo Kuma

The International Bamboo and Rattan Center, established in July 2000, is a non-profit science institution established by the National Forestry Administration. In 2004, the International Bamboo and Rattan Center cooperated with the China's Academy of Forestry to design and build Pingbian Primary School in Yunnan Province made of bamboo materials. The entire primary school's wall panels, trusses, and roofs were constructed using bamboo integrated plywood and bamboo weaving plywood. The technique of bamboo buildings is widely applied in the construction of the cross-water resort in Nan Con Son in Guangzhou Province. The most representative of the buildings is a bamboo bridge with an arch length of approximately 25 meters and a weight of 350 kilograms per square meter. The bamboo bridge is rounded and golden yellow. It's fully made of local bamboo in Nan Con Son ${ }^{[4]}$.

\section{The applicability of low-tech bamboo architecture in new rural construction}

With the continuous development of modernization and urbanization, rural buildings are increasingly affected by urban buildings. The phenomenon that "all villages represent the same appearance" has gradually emerged. At present, rural buildings are mostly made of bricks and concrete. The activities of bamboo construction have become increasingly popular with the concept of sustainable development.

\subsection{Good promotion of bamboo construction in the new rural construction}

Bamboo itself fits in well with the site as a natural material. Bamboo grows quickly and matures early, and has low-carbon life cycle. Replacing wood with bamboo can greatly reduce tree felling and forest destruction.

Bamboo is widely spread in China. In the construction of new rural areas, the replacement of wood, reinforced concrete and other building materials with bamboo can be widely promoted, which plays an extended and continued role in the traditional bamboo culture.

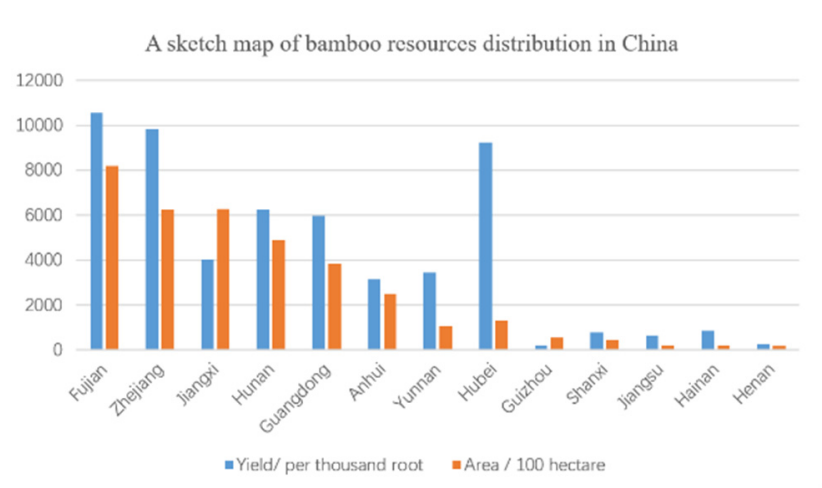

Traditional rural buildings are built in the way mainly due to the convenience of local materials and the economy of timber. Dai bamboo houses are the most classic bamboo-built residential houses and dry-type houses with unique characteristics created by the Dai people. Bamboo's outstanding structural performance, prominent low-carbon environmental characteristics, and perceived properties in color, arts, texture, and so on attract modern people to build by it.

\subsection{Good learnability of bamboo construction techniques}

Binding and joggling are the most common in traditional bamboo construction. People often use bamboo ropes and rattans to bind bamboos and iron wires that have long been used to increase the strength of binding. Joggling is a typical connected way of bamboos construction. Bamboo tenons are generally used to dig holes into thicker bamboos, and then the finer bamboos are joggled into the holes with iron wires or bamboo nails fixing.

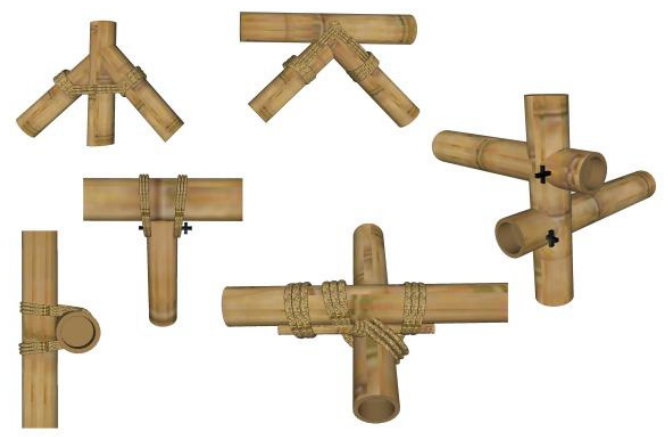

Figure 3. Combination of multiple connection modes

Techniques of the bamboo construction such as binding and joggling are low, and it is easy for people to learn and operate without requiring operators to be proficient in construction techniques.

\subsection{Good participation of bamboo construction techniques}

"The essence of architecture is the inhabitation of people. "Heidegger said.

Most of the key structural components of bamboo buildings are prefabricated in the factory according to the site environment and design requirements. After the components are completed, they can be directly sent to the 
site. The local workers will construct and integrate the bamboo materials on site. Compared with ways of traditional brick structured and concrete structured buildings, bamboo construction technique involves simple construction equipment and relatively small labor force. Villagers can directly participate in building construction.

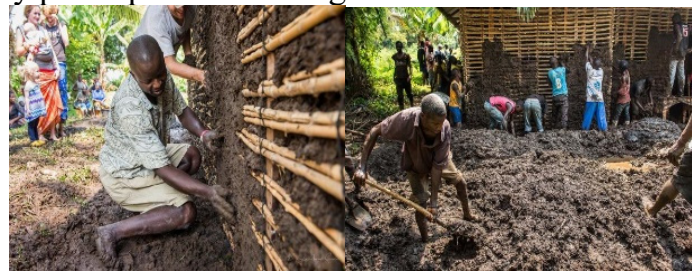

Figure 4. The inhabitants of Africa are building their homes with bamboo

Bamboo as a natural material can reflect the nature of architecture and the interaction between people and architecture and even between humans and nature. The low-tech and low-cost bamboo construction facilitates people's participation in the construction of buildings. People can create their own houses by weaving and lashing bamboo structures. The African people build their own houses by adopting bamboo mud wall technique. Every time a village is being built, villagers, regardless of whether they are young children or elder people, men or women, will help each other. The rich participation of bamboo construction can change people's rough views on traditional bamboo buildings, and continue their spatial feelings of bamboo's nature and austerity.

\section{Application and practice of low-tech Bamboo buildings in new rural construction}

\subsection{Application and practice of low-tech Bamboo buildings in new rural construction}

Low-tech refers to the traditional handmade technique before the industrial revolution. It conveys the idea that some traditional scientific and technological methods should be adopted with the development of high-tech in modern cities, which enable people to experience the essentiality of nature. Bamboo is one of the most important forest resources in China. It has a short growth cycle, high yield, and a wide range of uses. It has the advantages of being recyclable and easily degradable. As a result, bamboo has become an important resource in the construction of new countryside.

In the new rural construction, the use of natural materials is essential for sustained and stable development. Bamboo is not only a kind of plant that can be seen everywhere in some parts of China, but also a symbol of our country's culture. It should be adapted to local conditions in the construction of new rural areas based on local traditions, thus becoming a charismatic building material through its enormous design potential. People can adopt the "on-site" approach to invest in the construction of new rural areas through the use and promotion of bamboo materials.

However, the disadvantages of natural bamboo material have limited its use in construction to a large extent. The fundamental purpose of research and development by using bamboo material technique is to increase the popularity and popularity of bamboo materials by using existing technique under the premise of having abundant advantages of its natural bamboo resources, so that they can enter the lives of the public and become a new kind of environmental friendly building material. The processed bamboo material not only possesses the advantages of resources but can also effectively utilize the characteristics of bamboo itself. On the one hand, the bamboo material has the advantages of light weight and high strength, and its mechanical function is higher than ordinary wood materials. And the structural building built with bamboo material has a certain shock-absorbing effect, which can reduce the destructive impact caused by seismic waves. Compared with ordinary building materials, it can also help reduce casualties and increase the speed of rescue operations in the same location and at the same time even if a house collapses. On the other hand, China is taking a lead in bamboo industry, ranking the top lists in the world. It has developed a variety of bamboo decorative materials and bamboo building materials, such as bamboo plywood and bamboo reorganization materials. Bamboo-structured components can be processed at the factory and then delivered to the construction site upon completion of the processing. After that, only specifically fixed steps are required to be taken to assembly these components to finish the construction. The assembly site does not require large-scale engineering equipment but only the assembly technique. Therefore, the technique is low and the learnability is high. It helps improve the participation of the villagers in the later period and the promotion and popularization of the bamboo technique greatly. It will also help improve the industrialization level of the construction and increase the speed of construction. Besides, it will help reduce the cost of materials, and the cost of maintenance in the later period will be lower than that of ordinary building materials. These also further deepen the use and popularity of bamboo construction ${ }^{[5]}$.

The Bamboo building of the Zhouli Village convenience service center in Nanjing was built using bamboo structure. The architects first built the framework of the entire building based on the basic bamboo structure and then used a steel plate to connect the framework to consolidate the supporting system to make it more secure. Not only that, bamboo materials are widely used in the appearance and interior decorations of the building, which give it a rich performance, and at the same time increase the intuitive interaction between people and nature. It's no longer limited to concrete structures. These effects of the building can also reflect and prove in the effects of bamboo construction ${ }^{[6]}$ 


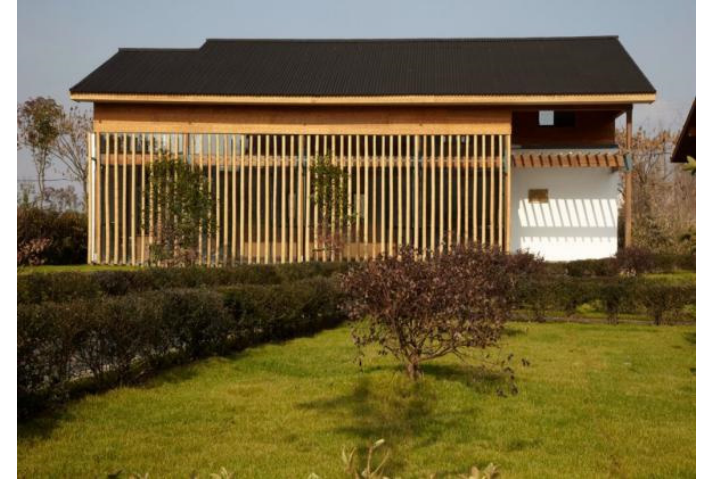

Figure 5. Nanjing Zhou Li village convenience service center

\subsection{Technical problems of bamboo construction in new rural construction}

\subsubsection{Durability of bamboo construction}

Due to the good benefits of bamboo in many aspects, bamboo construction has gradually become a new attraction in the construction of new rural areas. Because of the low technical cost of the technique, the enthusiasm of villagers to participate is extremely high. After the completion of bamboo construction, for itself, its existence should be much longer than furniture and decoration. But for the durability of the building, there are certain problems with bamboo.

In terms of moisture content, compared with wood, when we use bamboo, it is very difficult for them to dry before it is built. As a result, the bamboo will gradually dry after the completion of bamboo construction, causing the building to deform. For example, the bamboo chairs and bamboo benches bought in our daily lives will start to sway and rattle after one or two years of use although the connection of bamboo structures is relatively tight shortly after production. It is mainly because of the high moisture content of bamboo. While the water content of bamboo decreases with time, the density gradually increases. This causes the use of bamboo to have a big influence in buildings. (Figure 6) Therefore, we must pay attention

to

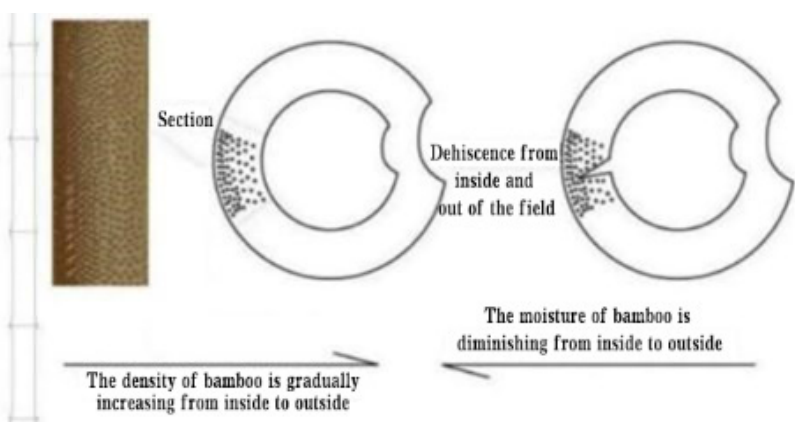

Figure 6. Change of bamboo density

the moisture content of bamboo before construction. On the other hand, in the process of using bamboo, its ability to withstand compressive stress should be great, but some bamboo materials bear poorer compressive stress, and the inner surface of the bamboo tube is prone to fractures and cracks. Therefore, the bamboo must be softened, which will

increase the moisture content of bamboo and improve the shape of bamboo.

Another problem is that the high sugar content of bamboo may result in galls and decay during the use of bamboo (Figure 7). This is the so-called cellulose with a relatively large amount of sugar or protein inside, leading to galls and decay of bamboo during use. This finally reduces the quality of bamboo or even completely loses its value. There are different solutions to deal with this problem. The physical methods include high-temperature method, smoke method, immersion method, micro wave method, ray method and so on. The advantages of these methods are no pollution and no residual poison. However, its disadvantage is that if it is not properly kept, there will be secondary mildew or infestation with insects. The chemical methods mainly include coating, impregnation, cooking, fumigation and pressurization. The advantage of these methods is that the effect of insect repellent and mildew prevention is prominent, while the disadvantage is that some of the agents are toxic and they are easy to cause pollution to the construction and the environment.

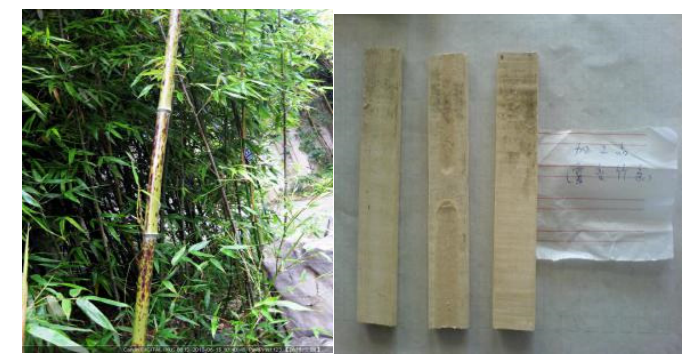

Figure 7. The worm moth and decay of bamboo

\subsubsection{The stability of bamboo construction}

The technique of binding and joggling is simple, but the strength and stability of bamboo construction have certain limitations. The material form of bamboo material is special hollow cylinder. When the bamboos are connected using binding and joggling techniques, the stress area is smaller than that of traditional woods, and the traditional bamboo construction node is not easy to process. The Bamboo House built by the Dai people of China has the problem of weak stability and low durability. Therefore, the Bamboo House has later gradually been replaced by wooden buildings.

The stability of buildings and the rationality of structural forces are the focus of many designers, who have high precision requirements for bamboo construction nodes. In the traditional bamboo structure, the forces between connected bamboo materials could directly influence each other. The bamboo material has the disadvantage of easy cracking. Therefore, it is most unstable at the bamboo construction nodes. In order to change the stability defect of the traditional bamboo construction, a new type of connection method, "bolt-cement connection method" is adopted, which mainly uses metal such as screws, bolts, and steel pieces for construction, at the bamboo node, force is firstly transmitted to the metal, and then transmitted to the bamboo connected with it. The use of metal components with strong load capacity at the nodes can effectively avoid this disadvantage and can exert the advantages of bamboo's 
tensile and compression resistance.

\section{Conclusions}

The application of bamboo construction technique in the rural construction is a return. The application of bamboo in construction has been a tradition since ancient times. Bamboo, in both China and other foreign countries, has been chosen by many village residents as the main material for building houses.

With the development of modern technology and people's increasing awareness of the marvelous mechanics performance and economic and ecological material properties of bamboo construction, the application of bamboo construction in the main green buildings for sustainable development is of significance in its ecology. In the new rural construction, low-cost, low-tech bamboo construction technique can be mastered and widely used by people.

The higher participation of bamboo construction increases the interaction between people and buildings. The architects have not only made a contribution to bamboo buildings in rural construction, but also have actively introduced and applied bamboo construction in the design and construction of new buildings. The technique displays aesthetic values of bamboo's nature and simplicity.The use of bamboo construction and the form and space of its demonstration are a good way to represent the return of architectural essence in the new rural construction. The cultural connotation and spirit embodied in bamboo construction and the architectural connotation revealed deserve reference and reflection of every new rural builder.

\section{Acknowledgment}

This paper is one of the staged achievements of science and technology innovation fund project of Wuhan University of Science and Technology(16ZRB158).

\section{References}

1. Han Dongqing, Ma Xiaodong, Wang Zheng [J], Urban Environmental Design (June 2010)

2. Tan Gangyi, Yang Liu, Construction of Bamboo Materials [M], Nanjing: Southeast University Press (2014)

3. Completion of World's First Bamboo Bridge with access to Vehicles by Hunan University [N], Hunan Daily (2007)

4. UAL City Architecture Studio, Dialogue between Architects and Bamboo, Bamboo Architecture, Bamboo Life (2015)

5. Xiao Jinsong, A Rough Analysis of Modern Bamboo Construction [J], Door and Window, (November 2016)

6. Ye Yun, Yuan Xinping, The Endogenous Pattern of Beautiful Rural Construction, Beijing: People's Press (December 2017) 